\title{
Segurança do trabalho na produção florestal
}

\author{
Pompeu Paes GUIMARÃES ${ }^{1 *}$, Vinícius Gomes de CASTRO ${ }^{1}$, Flavio Cipriano de Assis do CARMO ${ }^{2}$, \\ Nilton Cesar FIEDLER ${ }^{3}$, Renato César Gonçalves ROBERT ${ }^{4}$, \\ Fabrícia Nascimento de OLIVEIRA ${ }^{1}$
}

\author{
${ }^{1}$ Universidade Federal Rural do Semi-Árido, Mossoró, RN, Brasil. \\ ${ }^{2}$ Universidade Federal de Campina Grande, Patos, PB, Brasil. \\ ${ }^{3}$ Departamento de Engenharia Florestal, Universidade Federal do Espírito Santo, Jerônimo Monteiro, ES, Brasil. \\ ${ }^{4}$ Departamento de Engenharia e Tecnologia Florestal, Universidade Federal do Paraná, Curitiba, PR, Brasil \\ *E-mail: pompeupaes@yahoo.com.br
}

\begin{abstract}
Recebido em novembro/2018; Aceito em setembro/2019.
RESUMO: O objetivo do artigo é analisar os empregos diretos e os acidentes de trabalho ocorridos na produção florestal, em plantadas, nativas e atividades de apoio. Para cada atividade, no período de 2006 a 2014, foi contabilizado o número de empregos diretos, acidentes totais, registrados, típicos, de trajeto e doenças do trabalho e os acidentes não registrados. Foram ajustados modelos de tendência para cálculo das taxas de crescimento anual dos empregos diretos e dos acidentes de trabalho. Foi utilizada a correlação linear de Pearson para explicar a relação entre o número de empregos diretos e os acidentes da produção florestal. O número de empregos diretos gerados na produção de plantadas e nativas aumentou nos últimos 8 anos. Apenas para o setor de atividades de apoio decresceu o quadro de trabalhadores. Dentre os acidentes contabilizados, as plantadas apresentaram, em média, o maior número de acidentes, seguidos pelas atividades de apoio e produção de nativas. Muitos acidentes ocorridos não são comunicados, dando prejuízos aos acidentados quanto à reivindicação de seus direitos. Dos acidentes registrados o principal tipo corresponde ao acidente típico. Fortes correlações foram encontradas entre os empregos diretos e os acidentes totais para as florestas plantadas e atividades de apoio.
\end{abstract}

Palavras-chave: empregos diretos; acidentes; cadeia produtiva.

\section{Forest production work safety}

\begin{abstract}
The objective of this paper is to analyze the direct employment and work accidents that occurred in forest production, in plantations, native and support activities. For each activity, in the period from 2006 to 2014, the number of direct jobs, total, registered, typical, commuting and work-related accidents and unrecorded accidents were recorded. Trend models were calculated for the calculation of the annual growth rates of direct jobs and work accidents. Pearson's linear correlation was used to explain the relationship between the number of direct jobs and the accidents of forestry production. The number of direct jobs generated in plantation and native production has increased over the past 8 years. Only for the sector of support activities has the workforce declined. Among the accidents recorded, the planted had, on average, the largest number of accidents, followed by activities of support and production of natives. Many accidents occurred are not communicated, giving damage to the injured in claiming their rights. Of the accidents recorded the main type corresponds to the typical accident. Strong correlations were found between direct jobs and total accidents for planted forests and support activities. Keywords: direct jobs; accidents; productive chain.
\end{abstract}

\section{INTRODUÇÃO}

No ano de 2016, o setor florestal, considerando apenas a parcela do setor referente à florestas plantadas, empregou diretamente 510 mil pessoas, sendo que o número de postos de trabalho, diretos e indiretos, chegou a ordem de 3,7 milhões (IBÁ, 2017). No entanto, o setor florestal é um dos setores industriais mais perigosos, tendo um elevado índice de acidentes, doenças do trabalho e de aposentadorias precoces (OIT, 1998).

A produção florestal apresentou ainda os maiores valores, em média, de índice de mortalidade associados ao trabalho e, mesmo após treinamentos e conhecimento dos riscos não se reduziu o quantitativo de acidentes. As principais causas de acidentes na colheita florestal estão ligadas ao momento da derrubada e o risco consequente de "ser atingido" pela árvore (ASSUNÇÃO; CAMARA, 2011).

A comunicação dos acidentes em serviço é uma forma de contabilizar o alto índice de acidentes de trabalho e, através deste, analisar os fatores de risco associados aos mais recorrentes (SOUSA et al., 2010).

A falta de ferramentas adequadas e utilização de equipamentos inseguros, somado a não qualificação da mão de obra podem explicar o grande número de acidentes associados ao meio florestal (MEDEIROS; JURADO, 2013).

Os acidentes de trabalho foram analisados em setores florestais de uma instituição Federal de Ensino Superior de Minas Gerias tendo ocorrências ligadas a atos inseguros, seguido por condição insegura e por fator pessoal de 
insegurança, sendo observadas ainda poucas doenças do trabalho (VIANA et al., 2008).

Ao analisar as não conformidades principais referentes ao manejo florestal em áreas certificadas em Minas Gerais, para o quesito saúde e segurança, houveram as principais ocorrências ligadas ao descumprimento da NR-31, ao setor de colheita florestal, alimentação, falta de sinalização, sistema de avaliação e veículos inadequados (BASSO et al., 2012). O somatório de não conformidades, juntamente a um ineficiente padrão e critério de avaliação e monitoramento, além de não possibilitar a certificação, pode ser um agravante ao aumento do número de acidentes do trabalho.

Partindo deste pressuposto objetivou-se analisar os empregos diretos, os acidentes de trabalho ocorridos na produção florestal.

\section{MATERIAL E MÉTODOS}

A produção florestal reúne as atividades de produção de florestas plantadas, nativas e atividades de apoio conforme a Tabela 1.

Tabela 1. Descrição das atividades da produção florestal. Table 1. Description of forestry production activities.

Plantadas - Cultivo de espécies florestais madeireiras: plantio, replantio, raleamento, transplante e conservação florestal; abate de árvores; e viveiros florestais.

Nativas - Produção de lenha, carvão vegetal, estacas e postes a partir de madeira extraída de florestas nativas; colheita de produtos florestais não madeireiros tais como: látex, babaçu, cera de carnaúba, castanha-do-pará, resinas e outros produtos provenientes de nativas; e florestamento e o reflorestamento de nativas.

Atividades de apoio - As atividades de serviços florestais: inventário florestal; consultoria técnica de administração florestal; avaliação da madeira; semeadura aérea de espécies florestais; controle de pragas florestais; repovoamento florestal; transporte de toras somente no local de derrubada das árvores; $\mathrm{e}$ descarregamento da madeira.

Fonte: IBGE, 2017.

Para as três atividades relativas á produção florestal, foram contabilizados os empregos diretos (ED) compreendidos de 2006 a 2014 pelo Boletim SNIF (2017).

Os acidentes do trabalho ocorridos na produção florestal foram reunidos por meio de dados secundários disponibilizados pelo anuário estatístico de previdência social, no período de 2006 a 2014 (MPS, 2017). A Tabela 2 indica a definição dos acidentes analisados.

Tabela 2. Definições quanto aos acidentes contabilizados.

Table 2. Definitions of accidents recorded.

Totais - Somatório entre os acidentes registrados e não registrados Registrados - Acidentes em que houve Comunicação de Acidentes de Trabalho (CAT) e cadastro no Instituto Nacional de Seguridade Social (INSS). Abrangendo os acidentes típicos, de trajeto e as doenças do trabalho

Típicos - Acidentes originários da característica da atividade laboral desempenhada pelo acidentado.

De trajeto - Acidentes decorridos no percurso entre a residência e o local de trabalho, e vice-versa.

Doenças do trabalho - Acidentes ocasionados por qualquer tipo de doença profissional peculiar a determinado ramo da atividade.

Não registrados - Acidentes em que não houve CAT.

Fonte: IBGE, 2017.
Os resultados obtidos quanto aos empregos diretos e acidentes de trabalho ocorridos na produção florestal foram submetidos a uma análise de variância no delineamento inteiramente casualizado. As médias dos acidentes foram comparadas pelo teste de Tukey a 5\% de probabilidade, quando estes apresentaram diferenças estatísticas significativas.

Foram ajustados modelos de tendência para cálculo das taxas de crescimento anual dos empregos diretos, dos acidentes totais, registrados e não registrados por atividade da produção florestal, utilizando a metodologia de Almeida et al. (2009), e de Aguiar et al. (2014), (Equações 1, 2 e 3):

$$
\begin{aligned}
& \operatorname{Ln} E=\beta_{0}+\beta_{1} T+\varepsilon \\
& \operatorname{Ln} A=\beta_{0}+\beta_{1} T+\varepsilon \\
& c=e\left(\beta_{1}-1\right) 100
\end{aligned}
$$

em que: $E=$ Quantidade de empregos direitos no ano t; $A=$ Quantidade de acidentes no ano t; $T=$ variável tendência, em anos; $\varepsilon=$ termo de perturbação; $c=$ Taxa de crescimento composta.

Foi utilizada a correlação linear de Pearson $\left(r_{x y}\right)$ para explicar a relação entre o número de empregos diretos e os acidentes da produção florestal (Equação 4). Os coeficientes obtidos foram submetidos ao teste t, ao nível de $5 \%$ de significância (Equação 5).

$$
\begin{aligned}
& r_{x y}=\frac{S_{x y}}{S_{x} \cdot S_{y}} \\
& t=\frac{r_{x y \cdot \sqrt{(n-2)}}}{\sqrt{\left(1-r_{x y}^{2}\right)}}
\end{aligned}
$$

em que: $r_{x y}=$ coeficiente de correlação de Pearson, $S_{x y}=$ covariância e $S_{x}$ e $S_{y}=$ desvios padrão da variável x e variável $\mathrm{y}, t=$ valor da estatística e $n=$ número de valores observados.

\section{RESULTADOS}

No período de 2006 a 2014 foram criados um total 1.095.546 empregos diretos, na produção florestal. Neste mesmo período houve 29.700 acidentes, sendo comunicados 23.969 ocorrências. As estatísticas descritivas quanto aos empregos diretos, acidentes totais, registrados e não registrados na produção florestal mostradas na Figura 1.

Dos acidentes registrados, no périodo de oito anos, foram possíveis quantificar 21.873 acidentes típicos, 1.801 acidentes de trajeto e 295 doenças relacionados a produção florestal. Na Figura 2 subdividiu-se os acidentes registrados quanto ao tipo.

As taxas de crescimento quanto aos empregos diretos, acidentes totais, registrados e não registrados foram apresentadas na Tabela 3 .

As variáveis envolvidas quanto a segurança do trabalho na produção florestal foram correlacionas entre os empregos diretos e os acidentes totais, os registrados (típicos, de trajeto e doenças do trabalho) e os não registrados (Tabela 4). 


\section{$\begin{array}{lllll}0 & 20.000 & 40.000 & 60.000 & 80.000\end{array}$}

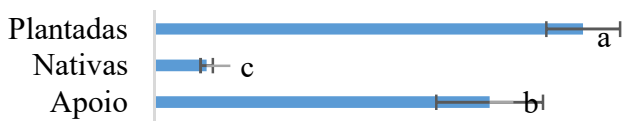

(a) Empregos diretos

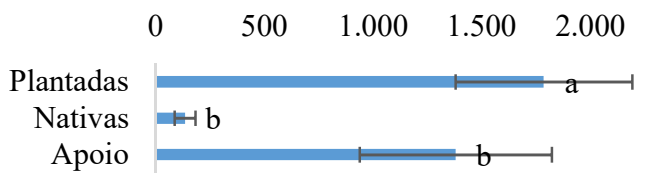

(b) Acidentes totais

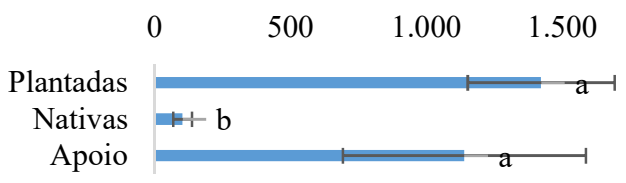

(c) Acidentes registrados

$\begin{array}{llllll}0 & 100 & 200 & 300 & 400 & 500\end{array}$

600

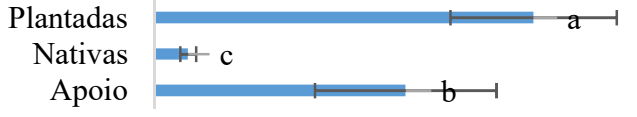

(d) Acidentes não registrados

Figura 1. Estatísticas descritivas quanto aos (a) empregos diretos, acidentes (b) totais, (c) registrados e (d) não registrados. Obs. Médias seguidas por uma mesma letra, não diferem entre si ao nível de $5 \%$ de significância pelo teste de Tukey.

Figure 1. Descriptive statistics for (a) direct jobs, accidents (b) total, (c) recorded and (d) unregistered. Obs. Means followed by the same letter, do not differ at the level of $5 \%$ of significance by the Tukey test.

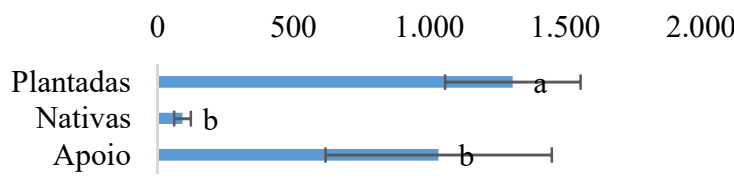

(a) Típicos

0

50

100

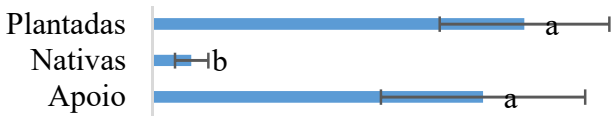

(b) De trajeto

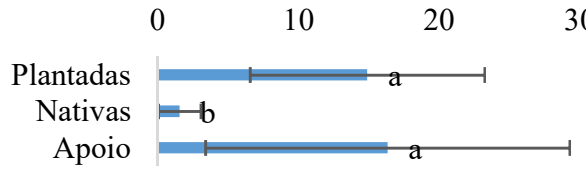

(c) Doenças do trabalho

Figura 2. Estatísticas descritivas dos acidentes registrados (a) típicos, (b) de trajeto e (c) doenças do trabalho na produção florestal. Obs. Médias seguidas por uma mesma letra, não diferem entre si ao nível de $5 \%$ de significância pelo teste de Tukey.

Figure 2. Descriptive statistics of typical (a) accidents, (b) of course and (c) diseases of work in forest production. Obs. Means followed by the same letter, do not differ at the level of $5 \%$ of significance by the Tukey test.
Tabela 3. Taxa dos empregos diretos e dos acidentes nas atividades da produção florestal.

Table 3. Rate of direct jobs and accidents in forestry production activities.

\begin{tabular}{llll}
\hline Taxa & Plantadas & Nativas & Apoio \\
\hline Empregos diretos & 1,73 & 0,13 & $-4,85$ \\
Acidentes totais & 2,85 & 12,62 & $-10,13$ \\
Registrados & 1,54 & 10,59 & $-10,92$ \\
Não registrados & $-3,10$ & 5,10 & $-8,99$ \\
\hline
\end{tabular}

Tabela 4. Correlações entre os acidentes de trabalho e os empregos diretos relativos a produção florestal.

Table 4. Correlations between work accidents and direct jobs related to forestry production.

\begin{tabular}{lll}
\hline & & Empregos Diretos \\
\hline \multirow{5}{*}{ Plantadas } & Acidentes totais & $0,9095 *$ \\
& Registrados & $0,8478^{*}$ \\
& Típicos & $0,8355^{*}$ \\
& Acidentes de trajeto & $0,8435^{*}$ \\
& Doenças do trabalho & $0,0991 \mathrm{~ns}$ \\
& Não registrados & $0,5593 \mathrm{~ns}$ \\
\hline \multirow{5}{*}{ Nativas } & Acidentes totais & $-0,2675 \mathrm{~ns}$ \\
& Registrados & $-0,1827 \mathrm{~ns}$ \\
& Típicos & $-0,1469 \mathrm{~ns}$ \\
& Acidentes de trajeto & $-0,3043 \mathrm{~ns}$ \\
& Doenças do trabalho & $0,6736 \mathrm{~ns}$ \\
& Não registrados & $-0,2111 \mathrm{~ns}$ \\
\hline \multirow{5}{*}{ Apoio } & Acidentes totais & $0,8792 *$ \\
& Registrados & $0,8498 *$ \\
& Típicos & $0,8345 *$ \\
& Acidentes de trajeto & $0,8387 *$ \\
& Doenças do trabalho & $0,8413 *$ \\
& Não registrados & $0,5770 \mathrm{~ns}$ \\
\hline em que: * = significativo ao nível de $5 \%$ pelo teste t de Student; e ns = não
\end{tabular}

\section{DISCUSSÃO}

4.1 Empregos diretos

O trabalho no setor de produção florestal envolveu mão de obra especializada como engenheiros florestais, motosserristas, tratoristas, técnicos florestais e motoristas, e como não especializada, ajudantes, cozinheiros e serviços gerais (OIT, 2018).

A atividade que gerou mais empregos dentre a produção florestal foi as florestas plantadas, com em média 63.980, seguidos pelas atividades de apoio $(50,009)$ e por último, florestas nativas, 7.738 empregos diretos (Figura 1a).

\subsection{Acidentes totais}

Com a mesma tendência de aumento do número de empregos diretos, houve elevação no número de acidentes totais na produção florestal relativa a florestas plantadas e atividades de apoio.

A produção de plantadas apresentou o maior quantitativo de acidentes de trabalho no período de 2006 a 2014, seguido pela atividade de apoio a produção florestal e florestas nativas, que não diferiram entre si (Figura 1b). Do total de 29.700 acidentes, $54,1 \%$ ocorreram em plantadas, $4,1 \%$ em nativas e $41,8 \%$ nas atividades de apoio a produção florestal. As atividades em florestas plantadas e de apoio corresponderam juntas a 95,9\% dos acidentes de trabalho contabilizados.

A extração florestal é uma das atividades contempladas na produção de florestas plantadas, analisando as condições de 
trabalho em região montanhosa da região do Vale do Rio Doce (MG) foi contabilizado que $29 \%$ dos trabalhadores já haviam sofrido acidentes de trabalho numa população de 56 trabalhadores avaliados. Estando expostos a situações que não contribuíam para manutenção de sua saúde (SILVA et al., 2009).

\subsubsection{Acidentes registrados e não registrados}

O número de acidentes registrados não diferiu entre si para as atividades de produção em florestas plantadas e atividades de apoio. Sendo registrados respectivamente, 78,3 e 79,2\% das ocorrências (período de 2007 a 2014, no ano de 2006 não houveram apontamentos sobre o número de acidentes não registrados), Figura 1c.

A cada 100 acidentes ocorridos, em média, 22,9 não serão comunicados em plantadas, 26,7 em nativas e 19,6 nas atividades de apoio (Figura 1d). O grande quantitativo de acidentes não registrados é prejudicial, além de não promover os devidos cuidados ao acidentado, a CAT funciona como registro de que o acidente teve decorrência do trabalho, sendo comprovado ou não posteriormente por perícia médica.

\subsubsection{Acidente típicos}

$\mathrm{O}$ acidente típico é aquele que ocorre pelo exercício do trabalho a respeito da empresa provocando lesão corporal ou perturbação funcional que cause morte ou redução, temporária ou permanente, da capacidade para o trabalho (BRASIL, 1991). O acidente típico envolveu 91,9\% dos acidentes registrados na produção de florestas plantadas, 88,3\% em nativas e $90,7 \%$ as atividades de apoio à produção. A média de acidentes típicos diferiam para as florestas plantadas, e não diferiram entre as florestas nativas e atividades de apoio (Figura 2a).

Conhecendo que a maioria dos acidentes de trabalho ocorridos na produção florestal foram acidentes típicos seria necessário abordar esta modalidade com maior ênfase nos futuros treinamentos e aprimoramentos dos trabalhadores dentro das empresas florestais.

Os acidentes típicos ocorridos em áreas rurais envolveram objetos cortantes, traumatismos ou lesões causadas por instrumento de trabalho, acidentes causados por plantas, queda/torção/escorrega e acidentes com objetos inanimados (TEIXEIRA; FREITAS, 2003).

As operações relativas ao corte das árvores pode acarretar em riscos relativos aos acidentes por imperícia na execução de atividades e no uso de equipamentos; acidentes diversos devido a clima desfavorável (vendavais, chuva, lama, etc.), animais peçonhentos, obstáculos (tocos, galhos, cipós, espinhos), queda de frutos e galhadas, queda por desnível do terreno, perfuração por tocos; acidentes causados pela sobreposição de operações; esmagamento do operador durante o traçamento; queda da árvore na direção contrária ao planejado; tombamento de árvores remanescentes; acidentes causados pelo próprio uso e desgaste da motosserra; acidentes causados durante a fuga do operador imediatamente após o corte, acidente com operador durante o deslocamento entre árvores; acidentes causados pelo rebote de cunhas durante a operação, rebote do tronco por rachadura; e acidentes com produtos químicos (NOGUEIRA et al., 2010).

\subsubsection{Acidentes de trajeto}

Pela lei $8213 / 91$ o acidente de trajeto é equiparado ao acidente de trabalho, acontecido no percurso da residência para o local de trabalho ou deste para aquela (BRASIL, 1991). Na lei 13.467/17, o tempo despendido pelo empregado até a efetiva ocupação do posto de trabalho e para o seu retorno, não será computado na jornada de trabalho, por não ser tempo à disposição do empregador (BRASIL, 2017).

Os acidentes de trajeto corresponderam a 7,1\%, 10,1\% e $7,9 \%$, respectivamente, para a produção florestal de florestas plantadas, nativas e apoio à produção florestal. Não houve diferença significativa entre os acidentes de trajeto em florestas plantadas e atividades de apoio. Já para as florestas nativas, os acidentes de trajeto diferiram dos outros acidentes de trajeto das demais modalidades (Figura $2 b$ ).

Uma explicação para os baixos valores de proporções apresentados é que, normalmente nas estatísticas oficiais, os acidentes de trajeto são subnotificados em comparação aos acidentes típicos ocorridos (CONCEIÇÃO et al., 2003).

De acordo com Teixeira e Freitas (2003), os principais meios de locomoção resultantes em acidentes de trajeto em áreas rurais foram: ônibus, a pé (parado, carregando, empilhando), bicicleta (duas rodas), caminhão, motocicleta, van, carreta, automóvel, animais quadrupedes (cavalo, pônei, jumento, burro, jegue), e caminhonete ou picape.

Para avaliar as condições de trabalho e segurança dos trabalhadores de colheita florestal foi percebido que a forma de deslocamentos dos trabalhadores quando terceirados ou próprios, respectivamente, era: automóveis $(21,3 \%$ e $35,2 \%)$, motocicletas $(4,9 \%$ e $10,8 \%)$, a pé $(9,8 \%$ e $16,2 \%)$ e por caminhões (6,6\% e 16,2\%), segundo Canto et al. (2007).

Para os acidentes rurais ocorridos em Santa Catarina, no período de 2008 a 2013, um quarto foi proveniente da produção de eucalipto e pinus, e $44 \%$ das ocorrências estavam ligadas às áreas de passagem, como estradas, e rodovias (LIRANE; ALMEIDA, 2015).

\subsubsection{Doenças do trabalho}

Mesmo em menores proporções as doenças do trabalho devem ser analisadas para redução de sua incidência em atividades florestais. Estas doenças representaram 1,0\%, 1,6\% e 1,4\% dos acidentes registrados para produção florestal de florestas plantadas, nativas e apoio à produção florestal, respectivamente. Em média, as ocorrências de doenças do trabalho relativas às florestas plantadas e atividades de apoio não diferiram entre si (Figura 2c).

Chama a atenção ao elevado desvio padrão das doenças do trabalho relacionadas às atividades de apoio, oscilando de 3,4 a 29,3 ocorrências no período de oito anos.

Teixeira e Freitas (2003) indicaram que as principais doenças do trabalho que acometem os trabalhadores em áreas rurais foram traumatismos ou lesões decorrentes de movimentos e lesões por esforços repetitivos, mal súbito e estresse.

Em análise à segurança do trabalho na colheita florestal, quanto a NR17 e 31, David et al. (2014) concluíram que, quanto ao corte semimecanizado as principais doenças do trabalho foram relativas a patologias ligadas à coluna vertebral, e quanto à atividade mecanizada, à repetitividade e monotonia da atividade.

4.3 Taxa de crescimento dos empregos diretos e dos acidentes

$\mathrm{O}$ setor de floretas plantadas apresentou o maior crescimento quanto aos empregos diretos relacionados, tendo aumento também no setor de nativas. $O$ único setor que reduziu o número de empregos foi o de atividades de apoio 
(Tabela 3). No período de 2006 a 2015 o setor florestal, segundo Moreira et al. (2010) contribui com, em média, 650 mil empregos formais, sendo que a maior parte dos empregos não estava nas atividades de campo (plantadas e nativas) e sim nas atividades voltadas a cadeia de transformação e agregação de valor (produção madeireira).

Ao mesmo tempo que houve aumento no número de empregos diretos, houve aumento no número de acidentes totais e registrados na produção de plantadas. Um fator positivo foi a redução no número de acidentes não registrados.

Para o setor de florestas nativas, mesmo com pequeno crescimento no número de empregos diretos, houve uma elevação nos acidentes totais, registrados e não registrados.

Os empregos diretos e número de acidentes tenderam a reduzir nas atividades de apoio, mostrando taxas negativas para o número de empregos, acidentes totais, registrados e não registrados.

A melhor forma de prevenir acidentes em atividades rurais é através do fornecimento de equipamentos de proteção individual (EPI), treinamento e monitoramento de sua utilização, conduzir a melhor forma de trabalho intercalado com pausas para descanso, o que entra em contradição quando a forma de remuneração ocorre por produção (ALVES; GUIMARAES, 2012).

\subsection{Correlação Empregos diretos e acidentes do trabalho}

Em relação a produção florestal em plantadas houve siginificância e forte correlação entre os empregos diretos gerados e os acidentes totais, registrados, típicos e de trajeto. Ou seja, com o aumento no número de empregos diretos ocorre elevação nos acidentes de trabalho, registrados, típicos e de trajeto.

Para as atividades de apoio, houve forte correlação entre os empregos diretos e os acidentes totais, registrados, típicos e de trajeto, como apresentado nas florestas plantadas. Além destes, também houve forte correlação dos empregos diretos e as doenças relativas ao trabalho.

Ao correlacionar os empregos diretos com os acidentes de trabalho, não houve significância entre os mesmos para o setor de florestas nativas.

A correlação entre os os acidentes não registrados e os empregos diretos não foi siginicativa para nenhuma atividade da produção florestal.

\section{CONCLUSÕES}

O número de empregos diretos gerados na produção de florestas plantadas e nativas aumentou nos últimos 8 anos. Porém, houve um aumento na tendência dos acidentes totais ocorridos. O setor de atividades de apoio decresceu seu quadro de trabalhadores e apresentou uma redução quanto a tendência das ocorrências de acidentes.

Dentre os acidentes contabilizados na produção florestal, as plantadas apresentaram, em média, o maior número de acidentes, seguidos pelas atividades de apoio à produção florestal e produção de florestas nativas. Grande parte dos acidentes ocorridos não são comunicados, dando prejuízos aos acidentados quanto à reivindicação de seus direitos. Dos acidentes registrados o principal tipo correspondeu ao acidente típico.

Fortes correlações foram encontradas entre os empregos diretos e os acidentes totais para as florestas plantadas e atividades de apoio. A ocorrência de acidentes pode ser minimizada pela intensificação das ações fiscais, campanhas nacionais de prevenção, conscientização quanto aos riscos e melhoria dos treinamentos e aprimoramentos quanto ao empregador.

\section{REFERÊNCIAS}

ALVES, R. A.; GUIMARAES, M. C. De que sofrem os trabalhadores rurais? Análise dos principais motivos de acidentes e adoecimentos nas atividades rurais. Informe Gepec. Toledo, v. 16, n. 2, p. 39-56, 2012.

ALMEIDA, A. N.; SANTOS, A. J.; SILVA, J. C. G. L.; BITTENCOURT, A. M. Análise do mercado dos principais produtos não-madeiráveis do estado do Paraná. Floresta, Curitiba, v. 39, n .4, p. 753-763, 2009. DOI: http://dx.doi.org/10.5380/rf.v39i4.16310

AGUIAR, G. P.; ROCHA, J. D. S.; SANTOS, A. J.; SILVA, J. C. G. L.; HOEFLICH, V. A. Comportamento do mercado dos principais produtos florestais nãomadeireiros da região nordeste do Brasil. Enciclopédia Biosfera, Goiânia, v. 10, n. 18, p. 983-992, 2014.

ASSUNÇÃO, A. A.; CAMARA, G. R. A precarização do trabalho e a produção de acidentes na colheita de árvores. Caderno CRH, Salvador, v. 24, n. 62, p. 385-396, 2011. DOI: http://dx.doi.org/10.1590/S010349792011000200010

SNIF_SISTEMA NACIONAL DE INFORMAÇÕES FLLORESTAIS. Boletim SNIF 2017. 2017. Disponível em:

http://www.florestal.gov.br/documentos/publicacoes/323 0-boletim-snif-2017-ed1-final/file> Acesso em: 30/08/2018.

BASSO, V. M.; JACOVINE, L. A. G.; ALVES, R. R.; NARDELLI, A. M. B. Contribuição da certificação florestal ao atendimento da legislação ambiental e social no Estado de Minas Gerais. Revista Árvore, Viçosa, v. 36, n. 4, p. 747-757, 2012. DOI: http://dx.doi.org/10.1590/S0100-67622012000400016

BRASIL, Lei $\mathbf{n}^{\circ} \mathbf{8 2 1 3}$, de 24 de julho de 1991. Dispõe sobre os planos de benefícios da Previdência Social e dá outras providências. Diário oficial da união, Brasília, DF 25/07/1991, Secção 1, p. 14809.

BRASIL, Lei ${ }^{\circ} \mathbf{1 3 . 6 4 7}$, de 13 de julho de 2017. Dispõe sobre as alterações a Consolidação das Leis do Trabalho (CLT), a fim de adequar a legislação às novas relações de trabalho. Diário oficial da união, Brasília, DF 17/07/2017, Secção 1, p. 1.

CANTO, J. L.; MACHADO, C. C.; SOUZA, A. P.; GARLET, A.; MIRANDA, R. M. A. C.; NOCE, R. Avaliação das condições de segurança do trabalho na colheita $\mathrm{e}$ transporte florestal em propriedades rurais fomentadas no Estado do Espírito Santo. Revista Árvore, Viçosa, v. 31, n. $3, \quad$ p. 513-520, 2007. DOI: http://dx.doi.org/10.1590/S0100-67622007000300017

CONCEIÇÃO, P. S. A.; NASCIMENTO, I. B. O.; OLIVEIRA, P. S.; CERQUEIRA, M. R. M. Acidentes de trabalho atendidos em serviços de emergência. Caderno de Saúde Pública, Rio de Janeiro, v. 19, n. 1, p. 111-117, 2003. DOI: http://dx.doi.org/10.1590/S0102$311 \mathrm{X} 2003000100012$

DAVID, H. C.; FIEDLER, N. C.; BAUM, L. Ergonomia e Segurança na colheita florestal: uma revisão entre a NR 17 e NR 31. Enciclopédia Biosfera, Goiânia, v. 10, n. 18, p. 1537-1550, 2014. 
IBÁ_INDÚSTRIA BRASILEIRA DE ÁRVORES (IBÁ). Relatório Ibá 2017. São Paulo: Ibá, 2017. 77p.

IBGE INSTITUTO DE GEOGRAFIA E ESTATÍSTICA. CONCLA: Comissão Nacional de Classificação. Disponível em: $<$ http://cnae.ibge.gov.br/?view $=$ secao $\&$ tipo $=$ cnae \&versa $\mathrm{o}=9 \&$ secao $=$ A $>$ Acesso em: 17/07/2017.

LIRANE, S. B.; ALMEIDA, E. D. F. Acidentes de trabalho no meio rural: perfil do trabalhador acidentado em Santa Catarina, Brasil. Revista Eletrônica Gestão \& Saúde, v. 6, n. 3, p. 2538-2532, 2015.

MEDEIROS, J. V.; JURADO, S. R. Acidentes de trabalho em madeireiras: uma revisão bibliográfica. Agrogeoambiental, Pouso Alegre, v. 5, n. 2, p. 87-96, 2013.

MOREIRA, J. M. M. A. P.; SIMIONI, F. J.; OLIVEIRA, E. B. Importância e desempenho das florestas plantadas no contexto do agronegócio brasileiro. Floresta, Curitiba, v. 47, n. 1, p. 85-94, 2017. DOI: http://dx.doi.org/10.5380/rf.v47i1.47687

MPS_MINISTÉRIO DA PREVIDÊNCIA SOCIAL. Anuário Estatístico da Previdência Social. 2017. Disponível em: $<$ http://www1.previdencia.gov.br/aeps2006/15_01_03.as p> Acesso em: 17/07/2017

NOGUEIRA, M. M.; LENTIONI, M. W.; PIRES, I. P.; BITTENCOURT, P. G.; ZWEEDE, J. C. Procedimentos simplificados em segurança e saúde do trabalho no manejo florestal. Belém: Instituto Floresta Tropical. Fundação Floresta Tropical, 2010. 80 p.

OIT_ORGANIZAÇÃO INTERNACIONAL DO TRABALHO. Cartilha sobre o trabalho florestal. 2018. Disponível em: $<$ http://www.florestal.gov.br/documentos/concessoesflorestais/monitoramento/8-cartilha-sobre-o-trabalhoflorestal/file $>$ Acesso em: $<21 / 09 / 2018>$
OIT_ORGANIZAÇÃO INTERNACIONAL DO TRABALHO. Segurança e Saúde no trabalho florestal: Código de práticas da OIT. 1998. Disponível em: $<$ http://www.fundacentro.gov.br/biblioteca/bibliotecadigital/publicacao/detalhe/2013/3/seguranca-e-saude-notrabalho-florestal> Acesso em: 19/07/1998.

SILVA, E. P.; MINETTE, L. J.; SOUZA, A. P.; BAÊTA, F. C.; FERNANDES, H. C.; MAFRA, S. C. T.; VIEIRA, H. A. N. F. Caracterização da saúde de trabalhadores florestais envolvidos na extração de madeira em regiões montanhosas. Revista Árvore, Viçosa, v. 33, n. 6, p. 1169-1174, 2009. DOI: http://dx.doi.org/10.1590/S010067622009000600019

SOUSA, A. P.; VIANNA, H. A.; MINETTE, L. J.; MACHADO, C. C. Avaliação das condições de segurança do trabalho no setores florestais de uma Instituição Federal de Ensino Superior. Revista Árvore, Viçosa, v. 34, n. 6, p. 1139-1145, 2010. DOI: http://dx.doi.org/10.1590/S0100-67622010000600020

TEIXEIRA, M. L. P.; FREITAS, R. M. V. Acidentes do trabalho rural no interior paulista. São Paulo em Perspectiva, São Paulo, v. 17, n.2, p. 84-90, 2003. DOI: http://dx.doi.org/10.1590/S0102-88392003000200009 http://www.scielo.br/pdf/spp/v17n2/a09v17n2.pdf

VIANNA, H. A.; SOUXA, A. P.; MINETTE, L. J.; MACHADO, C. C.; SANTOS, A. C.; SILVA, E. P. Análise dos acidentes de trabalho, enfatizando o setor florestal, em Instituição Federal de Ensino Superior. Cerne. Lavras, v. 14, n. 3, p. 234-240, 2008. 